\title{
Movement, impacts and management of plant distributions in response to climate change: insights from invasions
}

\author{
P. Caplat, P.-O. Cheptou, J. Diez, A. Guisan, B. M. H. Larson, A. S. Macdougall, D. A. Peltzer, \\ D. M. Richardson, K. Shea, M. van Kleunen, R. Zhang and Y. M. Buckley
}

P. Caplat, Dept of Earth and Ecosystem Sciences, Lund Univ., SE-223 62 Lund, Sweden. - P.-O. Cheptou, CEFE-CNRS, 1939 Route de Mende, FR-34293 Montpellier, France. - J. Diez, Swiss Federal Inst. of Technology (ETH Zurich), CH-8092 Zurich, Switzerland. - A. Guisan, Dept of Ecology and Evolution, Univ. of Lausanne, CH-1015 Lausanne, Switzerland. - B. M. H. Larson, Dept of Environment and Resource Studies, Univ. of Waterloo, Waterloo, Ontario N2L3G1, Canada. - A. S. Macdougall, Dept of Integrative Biology, Univ. of Guelph, Guelph, Ontario, N1G2W1, Canada. - D. A. Peltzer, Ecosystem Processes, Landcare Research, Lincoln 7640, New Zealand. - D. M. Richardson, Centre for Invasion Biology, Dept of Botany and Zoology, Stellenbosch Univ., Private Bag X1, Matieland 7602, South Africa. - K. Shea, Dept of Biology, The Pennsylvania State Univ., University Park, PA 16802, USA. - M. van Kleunen, Dept of Biology, Univ. of Konstanz, Universitätsstrasse 10, DE-78464 Konstanz, Germany. - R. Zhang, Harvard Forest, Harvard Univ., Petersham, MA 01366 , USA. - Y. M. Buckley (y.buckley@uq.edu.au), ARC Centre of Excellence for Environmental Decisions, The Univ. of Queensland, School of Biological Sciences, Queensland, 4072, Australia.

Prediction and management of species responses to climate change is an urgent but relatively young research field. Therefore, climate change ecology must by necessity borrow from other fields. Invasion ecology $\frac{\infty}{5}$ is particularly well-suited to informing climate change ecology because both invasion ecology and climate change ecology address the trajectories of rapidly changing novel systems. Here we outline the broad range है of active research questions in climate change ecology where research from invasion ecology can stimulate advances. We present ideas for how concepts, case-studies and methodology from invasion ecology can be adapted to improve prediction and management of species responses to climate change.

\begin{abstract}
A major challenge in this era of rapid climate change is to predict changes in species distributions and their impacts on ecosystems, and, if necessary, to recommend management strategies for maintenance of biodiversity or ecosystem services. Biological invasions, studied in most biomes of the world, can provide useful analogs for some of the ecological consequences of species distribution shifts in response to climate change. Invasions illustrate the adaptive and interactive responses that can occur when species are confronted with new environmental conditions. Invasion ecology complements climate change research and provides insights into the following questions: 1) how will species distributions respond to climate change? 2) how will species movement affect recipient ecosystems? And 3) should we, and if so how can we, manage species and ecosystems in the face of climate change? Invasion ecology demonstrates that a trait-based approach can help to predict spread speeds and impacts on ecosystems, and has the potential to predict climate change impacts on species ranges and recipient ecosystems. However, there is a need to analyse traits in the context of life-history and demography, the stage in the colonisation process (e.g. spread, establishment or impact), the distribution of suitable habitats in the landscape, and the novel abiotic and biotic conditions under which those traits are expressed. As is the case with climate change, invasion ecology is embedded within complex societal goals. Both disciplines converge on similar questions of 'when to intervene?' and 'what to do?' which call for a better understanding of the ecological processes and social values associated with changing ecosystems.
\end{abstract}

"All mankind is divided in three classes: those that are immovable, those that are movable, and those that move" (attributed to Benjamin Franklin). Replace "mankind" with "species" and this quote aptly describes the fate of species under climate change. Global climate change will likely result in species extinctions, disruption of ecosystem functioning, and movements of species at rates and scales unprecedented since the mid Holocene (Jentsch et al. 2007, Kelly and Goulden 2008). Consequently, a major challenge for ecology is to predict and manage global change impacts on species and ecosystems (Hoegh-Guldberg et al. 2008). Species' movement (or stasis) through a shift, expansion, or contraction of their ranges is a key focus of global change research (Thuiller et al. 2008, Doak and Morris 2010). Understanding and managing the ecological consequences of climate change demands answers to questions regarding: the responses of individual species and ecosystems and how society should deal with the resulting novel communities. 


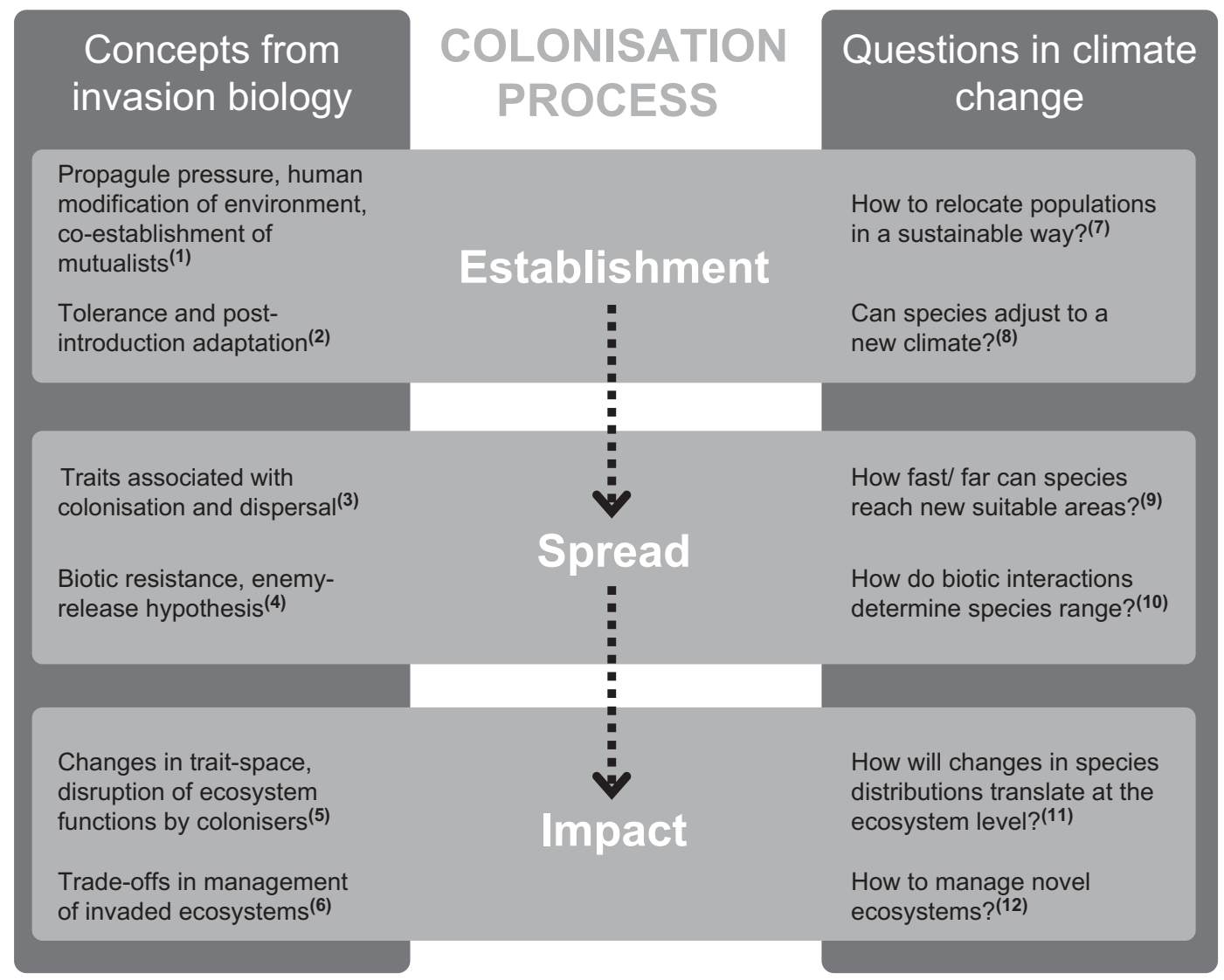

Figure 1. Concepts from invasion ecology (left hand side) at different stages of the colonisation process and their relevance to climate change questions (right hand side). For invasive species, introduction usually occurs due to human activity (either purposeful or accidental introduction). For native population movements, in a climate change context, purposeful introduction will only be relevant for translocated/ assisted migration processes. Superscript numbers point to the following references for illustration: (1) Richardson et al. 2011; (2) Schlaepfer et al. 2010; (3) Rejmánek and Richardson 1996; (4) Keane and Crawley 2002; (5) Pyšek et al. 2012; (6) Dickie et al. 2011; (7) Hoegh-Guldberg et al. 2008; (8) Etterson and Shaw 2001; (9) Elith et al. 2010; (10) Guisan and Rahbek 2011; (11) Wardle et al. 2011; (12) Hobbs et al. 2009, Schlaepfer et al. 2011.

We argue that the concepts, approaches, case studies, and model systems provided by invasion ecology can help resolve these questions by bringing a new perspective to climate change ecology. Invasion ecology has focused on the colonisation of species in new environments, giving insight into the processes underlying range-shifts in response to climate change (Fig. 1). Invasion ecology has also considered how characteristics of both the invading species and the invaded communities determine vulnerability and impacts. As invasions have been studied in most biomes of the world, they provide useful analogs for some of the ecological changes that will occur as a consequence of climate change.

Given the similarities between problems addressed by invasion and climate change ecology, a closer integration of the methods and findings of these fields is required. However, they have traditionally emphasised different drivers and effects of global change. Invasion ecology has focused more on historical reconstructions, demographic processes, species characteristics, and management (Richardson 2011). Climate change ecology has emphasised species niches and abiotic drivers of change (Guisan and Thuiller 2005) with only recent consideration of dispersal, intraspecific variation, demography, and species interactions (Jeltsch et al. 2008).
The emphasis of invasion ecology on human dimensions when considering management options could also be usefully transferred to the mitigation of climate change effects. The drivers of climate change are largely out of the direct control of ecosystem managers, making impact mitigation the primary management objective. Questions such as 'when to intervene?' and 'what to do?' require both ecological knowledge and an understanding of the social values associated with changing ecosystems. Invasion ecology's long history of considering the social and economic responses to changing ecosystems could be applied to efforts to respond to climate change impacts if deemed necessary.

Here, we discuss how concepts and methods in invasion ecology can provide analogs for how plants may respond to climate change. Although several studies have considered how invasive species respond to climate change (Thuiller et al. 2006), we know of no studies that explicitly consider the contributions of invasion ecology to climate change research. We do not review the response of invasive plants to climate change, nor do we offer a review of all the possible responses of plants to a changing climate (Walther 2010). With this forum piece, we hope to spark debate and further in-depth studies, using the full range of data, case-studies and concepts available to researchers from the intersection 
of invasion ecology and climate change ecology. To maintain breadth, we direct readers as often as possible to recent reviews. We identified three questions where invasion ecology and climate change ecology are complementary: 1) how will species distributions respond to climate change? 2) how will species movement affect recipient ecosystems? And 3) should we, and if so how can we, manage species and ecosystems in the face of climate change? We first address the causes of range-shifts, identifying characteristics of species and ecosystems that will enhance or impede changes in species' distributions. The second section focusses on the likely ecological effects of colonising species on recipient ecosystems. In the third section, we address management issues common to both invasion and climate change ecology, and the societal aspects of plant responses to climate change.

\section{How will species distributions respond to climate change?}

Plant species are expected to shift their range in response to changes in the spatial and temporal distribution of the environmental conditions that define their niche (Guisan and Zimmermann 2000). To project actual range-shifts, however, we need to assess the ability of species to persist under altered climatic conditions, or to colonise new areas as they become suitable (Best et al. 2007) (Fig. 1). To evaluate the latter, a simple approach is to apply historical rates of colonisation, but these projections typically underestimate mechanisms at play and their interactions (Midgley et al. 2006). For that reason, climate change literature has emphasised the incorporation of physiological or demographic mechanisms into climate-induced range shifts (Elith et al. 2010). Biological invasions show that usually, of all the species introduced in a given region, only a subset successfully establishes, and an even smaller subset becomes invasive. Research in invasion ecology has focussed on those that are successful at colonising new locations (Shea and Chesson 2002, Rout and Callaway 2009, Leifso et al. 2012, Petitpierre et al. 2012). We identify three groups of mechanisms controlling colonisation from the plant invasion literature including: 1) demographic mechanisms controlling population growth and spread, 2) biotic interactions determining the resistance of resident communities to colonisation event, and 3) mechanisms of plasticity and adaptation that allow individuals and populations to adjust to new conditions.

\section{Population growth and spread}

Predicting colonisation success may be achieved by identifying life-history traits that confer the ability to spread and establish in new environments. Invasion ecology has built on fundamental work on how plant traits affect plant performance and demographic rates (Cornelissen et al. 1997) and several studies have identified traits which are correlated with rapid spread ('invasiveness' in the terms of invasion ecology; van Kleunen et al. 2010). For example, Rejmánek and Richardson (1996) demonstrated that seed mass, age of maturity and frequency of reproduction events best separated invasive from non-invasive species of pines. Other invasion studies have identified traits that allow wind-dispersed species to disperse long distances, such as low seed falling velocity and plant height (Zhang et al. 2011, Caplat et al. 2012b). The study of traits associated with climate-induced migration is rare (but see Nathan et al. 2011). Amongst 171 forest plant species of western Europe, species with faster life-cycles shifted to higher elevations with changing climate more rapidly than species with slower life-cycles (Lenoir et al. 2008).

Species with traits favouring persistence in novel climates, may not necessarily have traits for wide dispersal, thereby limiting expansion (Moser et al. 2011). In this example, range stasis in species otherwise suited to climatic conditions outside of their current range could be mistakenly attributed to invasion resistance of the surrounding communities rather than to dispersal limitation. There are several limitations to using a trait based predictive approach. The trait approach often relies on correlations, and actual, but unobserved, traits conferring invasiveness might be correlated with other, 'neutral', traits that could be wrongly interpreted as important (van Kleunen et al. 2010). To predict species' colonisation it is therefore critical that both invasion and climate change ecology experimentally measure population responses where possible to untangle the mechanisms driving responses (Moser et al. 2011).

A challenge in applying the trait-based approach to forecasting climate change is caused by the interactions among climate, other sources of global change, traits, and population dynamics. Relatedly, the traits predicting colonisation and spread may be dependent on environmental context, so traits correlated with colonisation and spread under one set of conditions may not predict these processes in a different environment. Zhang et al. (2011) modelled demographic and dispersal responses to experimental warming on the spread of a wind-dispersed, invasive thistle. They showed that this species can keep pace with climate-induced range shifts through changes in vital rates and dispersal, knowledge that is critical for predicting how climate change will affect distribution. This research also suggests that models assuming rates of dispersal which do not change with climate may lead to incorrect estimates of distributional change.

The determination of how traits mediate invasion has promise for predicting how climate change will impact range shifts. Models combining local population dynamics and dispersal (Neubert and Caswell 2000) have been successfully applied to the spatial spread of several invasive species (reviewed by Caplat et al. 2012a) and more recently, potential climate change colonisers (Nathan et al. 2011, Zhang et al. 2011, Bullock et al. 2012). When used in conjunction with trait-based approaches, these models can identify mechanistic drivers of population expansion that enable better predictions of climate responses. However, invasion ecology demonstrates that the search for traits to explain which species will be able to track changing climates is likely to be context dependent. Important contingencies will include the stage of the colonisation process (e.g. spread, establishment or impact) (Pyšek et al. 2009); landscape structure including the grain, extent, and distribution of suitable habitat (Coutts et al. 2011); life-history and demography; dispersal processes; human intervention (Pyšek et al. 2010); and the novel abiotic and biotic conditions under which those traits are expressed (see next section, Resistance of resident communities). 
Some important differences may exist between climatechange colonisers and invasive species. Invasive species have often been purposefully introduced and selected for traits that allow high establishment rates in the area where they were introduced, through farming and forestry practices (Pyšek et al. 2010). Native colonisers do not necessarily possess the traits that pre-adapt them to the novel environments created by climate change. We might therefore expect a higher probability of colonisation for purposefully introduced non-natives (a large proportion of invasives) than for distribution shifts in response to climate.

Spatially explicit models have been used to predict the future ranges of invasive species based on a combination of information about species' traits and performance in native and invasive ranges (Latimer et al. 2009). A similar approach could integrate information from current ranges and future potential ranges to predict suitability of new sites for expansion. Next generation models are likely to focus on integrating available data with process-based demographic models describing population dynamics (Pagel and Schurr 2011).

\section{Resistance of resident communities}

Species interactions may slow down distributional shifts through a range of mechanisms, particularly when resident species restrict the establishment, growth, or fecundity of colonisers (Caplat et al. 2008, Thuiller et al. 2008). Overcoming this resistance of recipient communities is essential for both invasion and climate induced range shifts. How do new colonisers successfully establish and persist in preexisting communities? Colonisers may possess traits that are absent in the recipient community, and thus allow them to expand quickly (Leifso et al. 2012), a process which may be favoured by an absence of co-evolutionary history between colonisers and the recipient community (Hallett 2006). The Enemy release hypothesis (ERH) posits that invasive species gain a competitive advantage when enemies or pathogens from their home range are absent, compared with native resident species which possess the full suite of natural enemies (reviewed by Keane and Crawley 2002). However, an increasing number of studies have observed no performancebased adjustments by dominant invaders between their native and invaded ranges (Firn et al. 2011), indicating that enemy release is not always important for invasion. While the lack of enemies does not necessarily ensure invasion success, there is less evidence about how the presence or absence of mutualists affects invasibility. Both beneficial and harmful aboveground-belowground interactions (Dickie et al. 2010) are increasingly recognized as crucial for projecting future plant distributions (Fridley et al. 2011), and species distributions might reflect the distribution of their competitors, predators, parasites or mutualists.

Invasion ecology has distinguished between species that benefit from a change in conditions, "passengers of change", and species that drive the changes, "drivers of change" (MacDougall and Turkington 2005). The implication of this distinction is that impacts may be attributed directly to the invasion, when in fact the invasion is just a consequence of underlying environmental changes. Invasibility of a community can therefore be circumstantial (Leifso et al. 2012), for example when colonisers are favoured by human intervention, such as the combination of the eradication of native communities and the introduction of colonisers' propagules (Lonsdale 1999). Studies at a large scale (i.e. encompassing a variety of environmental conditions) have found positive relationships between species richness and risk of invasion (invasibility), probably due to underlying factors that favour the diversity of both native and non-native communities, such as propagule supply, disturbances and environmental heterogeneity (Levine 2000, Melbourne et al. 2007). Colonisers thus benefit from a diverse environment, regardless of their traits. We might expect this pattern to be maintained for climate change induced range movements, i.e. that species-rich regions will have capacity to accept new colonisers as long as climate impacts do not reduce environmental variability. This simple analogy with invasion ecology however does not take into account how the processes maintaining species richness may alter with changing climate. Similarly, because climate change is expected to alter disturbance regimes (e.g. drought, fire frequency), climate may play an important role by creating novel conditions to which colonisers might not be adapted. Indeed, invasion studies have consistently identified traits that enable species to colonise disturbed environments (Richardson and Cowling 1992, Richardson 2011).

A key feature of climate change is indirect effects on species, through modifications of competitive interactions. Climate can influence species' range shifts by altering competitive outcomes in favour of the colonising species (Walther 2004), while effects of climate change can be buffered through plasticity-based adjustments by resident species or herbivory (Fridley et al. 2011). There can also be contingencies in the outcome of interactions between colonising and resident species depending on latitudinal position (e.g. facilitative coexistence in some regions; competitive displacement in others, Richardson et al. 2012). In some cases, the indirect effects of climate change may be positive, where the novel conditions favour the coloniser. For example, invasion by the introduced grass Agropyron cristatum on the northern Great Plains of North America is driven, in part, by its high resource uptake conferring a competitive advantage that dramatically suppresses community diversity. However, a positive effect of climate change, warmer springs and wetter summers, also favours the early phenology and high summer water demands of this invader compared to native grasses (MacDougall et al. 2008).

An important challenge for climate change ecology will be incorporating community assembly rules into modelling frameworks to predict changes in communities following range shifts or invasions. For instance, the recently developed SESAM framework (Guisan and Rahbek 2011) combines species pool, species distribution models, dispersal models, and ecological assembly rules to predict species assemblages in space and time. To test such models, invasions can provide real-world examples of native communities affected by the range expansion of one or several species.

\section{Plasticity and adaptation mechanisms}

Phenotypic plasticity might allow plants to tolerate or take advantage of environmental change. While many studies have quantified phenotypic plasticity or tolerance in response to climatic variables (Lloret et al. 2012), we are 
not aware of any study which has correlated plasticity with changes in distribution in response to abiotic change. However, several studies have suggested that phenotypic plasticity should characterize many invasive plant species (Baker 1965, Richards et al. 2006). A recent meta-analysis showed that invasive species are usually more responsive to increased resource levels than native species, although plasticity did not appear to improve fitness (Davidson et al. 2011). Another recent meta-analysis showed that biomass response to increased resources was positively associated with global invasiveness of non-native species, but did not find an association between morphological plasticity and invasiveness (Dawson et al. 2012). Multi-species comparative studies also suggest that environmental tolerance is frequently associated with colonisation ability (Schlaepfer et al. 2010, van Kleunen et al. 2011). Although it is not always clear how plants achieve environmental tolerance, tolerance is advantageous for invasion and, hence may also be important for maintaining and moving species' ranges in response to climate change.

In addition to phenotypic plasticity, adaptive evolution might allow plant species to tolerate climate change. It has been shown already that rapid evolution in response to climate fluctuations is possible in some species (Franks et al. 2007), but also that adaptive evolution of plants in response to global warming may be constrained due to genetic correlations among traits (Etterson and Shaw 2001). Invasion biology can provide additional insights in the importance of evolutionary adaptation to new climatic conditions since there has been a strong focus on evolutionary change to understand why some species colonise new areas better than others (Hahn et al. 2012). One reason may be rapid evolution, which has been shown to occur during plant invasions (Colautti et al. 2009).

The evolution of increased competitive ability (EICA) hypothesis postulates that plants in the invasive range may have increased their competitive ability at the cost of resistance against enemies (Blossey and Notzold 1995, Hierro et al. 2005). Climate change might lead to similar trajectories if plants escape their natural enemies when shifting range. Similarly, plants after migration might not encounter suitable pollinators if the latter cannot track suitable climate as well as their host plants (Berg et al. 2010). Studies on invasive plant species have shown that absence of pollinators in the new range can result in evolution of self-compatibility and apomixis (Barrett et al. 2008). Range shifting might also impose strong selection on traits that promote dispersal. Shifts in dispersal traits across a species' range has been reported in plants (Darling et al. 2008). We know from recent studies that evolutionary changes in dispersal can be rapid (Cheptou et al. 2008), which could dramatically affect the colonising dynamics of range-shifting species.

The evolutionary forces that mediate biological invasions may differ somewhat from range changes under climate change due to the supposed lack of genetic variance in invasions caused by bottlenecks (Lee 2002). A strong founder effect can occur in transcontinental invasion, or island invasion, where gene flow is limited. However, there are many examples where repeated introductions have led to high within-population genetic variance (Bossdorf et al. 2005). Evolution in the introduced ranges can also contribute to evolutionary novelties (e.g. by hybridization, Lavergne and Molofsky 2007), especially when small isolated founder populations undergo rapid divergent evolution. Many cases of hybridization between related species that used to be geographically separated have been documented through invasion studies (Sloop et al. 2011, Ward et al. 2012), and can give insights into the likelihood of similar trajectories when species move in response to climate change.

Invasions have shown that migration between ancestral populations and new populations affect subsequent evolutionary dynamics, which sometimes slows spread to new regions through, for example, outbreeding depression (Wilson et al. 2009). Clearly, migration between ancestral and novel populations is central when considering the possibility of climate induced range shifts.

Because climate change ecology is principally concerned with contiguous range shifts rather than spatially dislocated invasion episodes, it seems likely that a lack of genetic variance due to founder effects will be less frequent for species responding to climate change (Cheptou 2012). However, regular gene flow from central to peripheral populations may slow adaptation at the range margins, potentially limiting range expansion ('outbreeding depression', Kirkpatrick and Barton 1997). In cases of deliberate introductions such as managed relocation, evolutionary dynamics may be more similar to those documented for invasions, see for example the abundant literature on the risk of transgene flow for genetically modified crops (Heuberger et al. 2010). Insights from invasion ecology are thus likely to be helpful in planning effective assisted colonisations.

\section{How will species movement affect ecosystems?}

\section{Direct effects of colonisers on ecosystems}

Understanding how colonising species change ecosystem function can help us to anticipate the effects of species' movements in response to climate change. Invasion ecology has shown a range of effects on recipient communities such as increased primary productivity (Bradley et al. 2006) and increased resource availability through nutrient accretion or rapid litter decomposition (Wardle et al. 2011). Colonising species can also affect biogeochemical cycles. For example, non-native colonising plants can have deeper root systems than resident native species, thus allowing invaders greater access to water or nutrients (Hierro et al. 2005).

Progress in understanding the variation of coloniser impacts on ecosystem processes, including biogeochemical cycles, can be made by linking functional traits with ecosystem processes. The response of novel ecosystems to climate change will thus be influenced by the distinctiveness and importance of functional traits as well as the relative abundance of the colonisers and species lost from the system (Wardle et al. 2011, Pyšek et al. 2012). A fundamental question that remains unanswered is the degree to which traits which are favoured under climate change (e.g. drought tolerance) will impact the structure and function of communities. Community or ecosystem attributes could be maintained, altered or enhanced depending on the species richness and 
composition of communities which lose and gain species due to climate change.

\section{Long-term consequences of species movement on ecosystems}

The role of colonising species on long-term changes in ecosystem processes is poorly understood, but the growing literature on the subject in relation to invasions suggests that large-scale persistent changes are likely (Vilà et al. 2011). In the context of climate-mediated movements, these changes can exacerbate functional declines already underway via direct climatic impacts. Indirect effects can also manifest over decades, and these are potentially far more important and damaging than short-term direct effects. For example, direct carbon losses from herbivory by introduced deer in New Zealand typically affects $<1 \%$ of forest carbon stocks. However, these small short-term effects on carbon stocks belie the important indirect long-term effects of deer on carbon sequestration including altered successional trajectories, reduced recruitment of tree species, and shifts in the relative dominance of canopy species towards unpalatable species (Coomes et al. 2003). Similar cases of complex species interactions leading to long-term, dramatic consequences on ecosystems ("invasional meltdown" sensu Simberloff and Von Holle 1999) have been documented in invasion studies, and these provide crucial insights on potential indirect effects of climate change on ecosystems.

Climate change can also increase community turnover by altering disturbance regimes (Jiménez et al. 2011), or by weakening the ability of resident species to recover from preexisting disturbances, such as fire or grazing. The weakening of post-disturbance recovery may create invasion windows for colonising species, which may in turn increase the frequency or intensity of disturbance events. Some of the best documented examples of this feedback between colonising species and disturbance regimes are invasive grasses that have increased fire frequency or intensity compared to uninvaded systems (Brooks et al. 2004).

\section{Should we, and if so how can we, manage species and ecosystems in the face of climate change?}

In this section, we focus on how experiences with managing invasive species can inform the management, where appropriate, of species and ecosystems under climate change. Species range-shifts might be considered more positively than species invasions because they occur 'naturally' (with the exception of cases of assisted colonisation, see below). However in some circumstances, native species expanding their ranges may dramatically alter ecosystem services and be perceived as negatively as invasive non-native species, thus calling for similar management practices. Whether or not to manage an ecosystem which is affected by climate-induced species movements will depend on available resources, societal values and the feasibility of management to ameliorate negative impacts. We explore the social and decision making context of managing species' altered distributional ranges and then look in more detail at two management issues: assisted colonisation and moving beyond single species management.

\section{Decision theory and societal values}

If we know what facilitates the establishment, expansion, and impact of invaders, then we have grounds for an informed choice of management strategy (Ramula et al. 2008). Economic and social constraints must also be considered, which can be formally addressed within a decision-theory framework (Shea et al. 1998). If it is considered a desirable management goal to reduce impacts of naturally rangeshifting species, this will require interventions aimed at limiting spread and/or impacts rather than eradication. Tools have been developed to help achieve this goal when dealing with invasive plants, and these may provide benchmarks for efforts aimed at mitigating perceived negative impacts of climate change colonisers.

However, setting and implementing management requires an awareness of how society perceives the problem. Invasion ecology operates within the context of changing societal norms with attitudes towards invasive species changing through time and for different stakeholders (Mackenzie and Larson 2010). In the context of climate change, it is important to recognize that scientific and societal norms are already changing (Hobbs et al. 2006). Questions about whether and how to manage new species will arise with increasing frequency through a broad range of stakeholder values as well as potential conflicts related to alternative goals and pathways for climate change mitigation. We know from cases of plant invasions that the goals of biodiversity conservation are not necessarily concordant amongst study organisms or trophic levels, or congruent with other management goals such as carbon sequestration or water availability. Invasion by the non-native tree Corsican pine (Pinus nigra) in New Zealand, for example, rapidly increases total C sequestration but has contrasting effects on biodiversity that depend on the taxonomic group studied (Dickie et al. 2011). Biodiversity conservation can also lead to fuel accumulation with consequent increase in fire frequency or intensity making conflicts between urban management and biodiversity conservation more common (Driscoll et al. 2010).

\section{The case of assisted colonisation}

Directly moving populations, or facilitating their movement, may be an important strategy for species threatened with extinction by climate change. Species relocations and assisted colonisation have been suggested (Hoegh-Guldberg et al. 2008) and carried out (Vitt et al. 2010). However the regulatory and scientific frameworks needed to optimize implementation have lagged (Richardson et al. 2009, McDonald-Madden et al. 2011).

Humans have purposefully introduced species for thousands of years and, consequently, the invasion literature is rich with examples of the efforts needed to establish species in novel locations (Van der Veken et al. 2008, Richardson et al. 2011). It has been suggested to use past invasions to learn about the consequences of assisted colonisation (Carrete and Tella 2012). For instance, a recent study of invasive grassland species (Firn et al. 2011) found that 
abundance in the native range is correlated with abundance in the introduced range, so we may expect relocated species that are rare in their native ranges to be rare in their non-native ranges also. However, there are several counterexamples in the invasion literature of species, rare in their native range, that are subsequently highly invasive in their non-native range (e.g. Monterey pine Pinus radiata).

Direct comparisons between deliberate species relocations, such as biological control, and species relocations for climate change adaptation are rare. Case studies and meta-analyses of biocontrol processes and outcomes can be used to learn about how best to maximise the success of species relocations and minimize risks of direct and indirect negative effects. There may be useful insights regarding regulating species relocation from the successes and failures of biocontrol introductions (Jarvis et al. 2006). A large body of literature that has focused directly on agent discovery and collection (Heard and Pettit 2005), ex situ rearing and sanitary procedures (Mackauer 1976), introduction risk analysis (Jarvis et al. 2006), host testing (Barton 2004), establishment strategies (Grevstad 1999), post hoc impact assessment (Louda et al. 2003), and monitoring and evaluation (Yeates et al. 2012) has been overlooked in the species relocation context. There is also a growing literature focussed on quantifying the risks associated with the introduction and naturalisation of genetically modified organisms (Levidow 2001).

In some cases, predicting whether relocated species will become invasive is not possible, particularly as many species exhibit lags between establishing in a new location and becoming invasive (Ricciardi and Simberloff 2009). Therefore, preparing for potentially negative effects of assisted colonisation is crucial. Past experiences with species introductions provide guidance with regards to society's response to species' movements (wanted or unwanted), although we still have limited understanding of how different stakeholders will respond to proposed management and when conflicts will arise (Gobster 2011). Early work suggests a range of social values for particular scenarios that create difficult trade-offs for decision makers (Richardson et al. 2009). Decisions will have to be sensitive to the specificity of individual cases to negotiate the conditions under which assisted colonisation should be undertaken (Minteer and Collins 2010).

\section{Beyond single-species management}

Both climate change ecology and invasion ecology run the risk of focusing on single species actions at the expense of broader ecosystem views (Montoya and Raffaelli 2010). Climate change ecologists can benefit from following wholeecosystem approaches from the outset rather than falling into the same trap as invasion ecologists and managers, who have tended to focus on individual species. Consequently, there have been repeated calls for the integration of invasive species management goals and processes into a broader, ecosystem-level restoration context (Zavaleta et al. 2001, Russell et al. 2012). Management focused on a single species may have indirect effects, such as re-invasion after control (Buckley et al. 2007), may have direct (Louda et al. 2003) and indirect off-target impacts (Carvalheiro et al. 2008), and may compromise broader ecosystem restoration goals (Reid et al. 2009). The goals of invasive species management are rarely elaborated beyond the proximate reduction in density or extent of the target species when, in fact, invader control may be just one of a suite of required actions.

It remains to be seen how ecologists, and society more generally, will adapt to novel ecosystems formed by the confluence of climate change, invasive species, and increasing human disturbance (Seastedt et al. 2008). Ecological systems have traditionally been afforded an intrinsic value based on their fidelity to systems of the past, but this approach will be increasingly anachronistic as they change in response to climate and other concurrent drivers (Minteer and Collins 2010). Some conservation biologists might view novel ecosystems as 'lemons' from which we can make little lemonade, yet they serve important ecological functions (Hobbs et al. 2006). Conservation philosophy and goals will therefore need to adapt to a changing world. Some researchers call for a wider adoption of non-native species into conservation management (Schlaepfer et al. 2011). Whether or not this view is widely embraced, it is clear that more pragmatic conservation approaches will be required in many cases as non-native species become increasingly widespread and as climate-driven range changes become more widely recognized.

Conservation goals also depend on the current state of the ecosystem. In some cases, it may not be possible to restore novel ecosystems to a previous desirable state, so managers might instead focus on retaining valued ecosystem services (Hobbs et al. 2009). But where ecosystems are not so modified ('hybrid ecosystems'), managers may strive to maintain or restore diversity and structure, especially when they are faced with relatively few drivers of change. In either case, managers will need to set clear objectives for the managed system to achieve any kind of climate adaptation success. In this respect, both invasion biology and climate change ecology have the same difficult road to travel.

\section{Conclusions and future research directions}

We have shown how invasion ecology can be used to inform three key areas of climate change research. Progress using the perspective of invasion ecology to complement existing climate change research relies on 1) understanding and predicting species' movements, through identification of attributes that confer the ability to disperse, establish, and persist in new areas; 2) understanding and predicting the response of ecosystems to colonisers and 3) controlling the spread of unwanted species or managing the movement of species, which can enhance attributes of communities and ecosystems that society values.

We hope that the problems encountered during decades of invasion research can help guide research and management of species and ecosystem responses to climate change. Our review offers a starting point for researchers to quickly identify the parts of the literature that are the most relevant to that goal. Invasion ecology only has a fraction of the answers that we need in order to better live in and manage our changing world. However, we believe that collaborations and synergies between these two fields will lead to better outcomes for ecosystems threatened by all forms of global change. 
Acknowledgements - We thank the Ecological Society of America for supporting the organized oral session "Plant Responses to Climate Change: Lessons from Invasions" at their annual meeting 2011. For funding we thank: Australian Research Council Centre of Excellence for Environmental Decisions and the Australian Government's National Environmental Research Program (YMB), CSIRO's OCE postdoctoral program (PC), Social Sciences and Humanities Research Council of Canada (BMHL). We acknowledge support from DST-NRF Centre of Excellence for Invasion Biology and the Working for Water Programme through their collaborative research project on "Research for Integrated Management of Invasive Alien Species" (DMR), SNF, grant CRSI33_130409/1 (MvK), New Zealand Ministry for Science and Innovation (contract C09X0502) (DP), NSF grant no. DEB0815373 (KS), MacMaster Foundation at CSIRO and the Herbette and 450e Foundations at the University of Lausanne (AG). We also thank Bruce Webber and Natalie Kerr for their comments on the manuscript.

\section{References}

Baker, H. G. 1965. Characteristics and modes of origin of weeds. - In: Baker, H. G. and Stebbins, G. L. (eds), The genetics of colonising species. Academic Press, pp. 147-168.

Barrett, S. C. H. et al. 2008. Plant reproductive systems and evolution during biological invasion. - Mol. Ecol. 17: 373-383.

Barton, J. 2004. How good are we at predicting the field host-range of fungal pathogens used for classical biological control of weeds? - Biol. Control 31: 99-122.

Berg, M. P. et al. 2010. Adapt or disperse: understanding species persistence in a changing world. - Global Change Biol. 16: 587-598.

Best, A. S. et al. 2007. Which species will succesfully track climate change? The influence of intraspecific competition and density dependent dispersal on range shifting dynamics. - Oikos 116: 1531-1539.

Blossey, B. and Notzold, R. 1995. Evolution of increased competitive ability in invasive nonindigenous plants: a hypothesis. - J. Ecol. 83: 887-889.

Bossdorf, O. et al. 2005. Phenotypic and genetic differentiation between native and introduced plant populations. - Oecologia 144: $1-11$.

Bradley, B. A. et al. 2006. Invasive grass reduces aboveground carbon stocks in shrublands of the western US. - Global Change Biol. 12: 1815-1822.

Brooks, M. L. et al. 2004. Effects of invasive alien plants on fire regimes. - Bioscience 54: 677-688.

Buckley, Y. et al. 2007. Disturbance, invasion and re-invasion: managing the weed-shaped hole in disturbed ecosystems. - Ecol. Lett. 10: 809-817.

Bullock, J. M. et al. 2012. Modelling spread of British winddispersed plants under future wind speeds in a changing climate. - J. Ecol. 100: 104-115.

Caplat, P. et al. 2008. Interactions between climate change, competition, dispersal and disturbances in a tree migration model. - Theor. Ecol. 1: 209-220.

Caplat, P. et al. 2012a. Modeling population dynamics, landscape structure and management decisions for controlling the spread of invasive plants. - Ann. N. Y. Acad. Sci. 1249: 72-83.

Caplat, P. et al. 2012b. Seed terminal velocity, wind turbulence, and demography drive the spread of an invasive tree in an analytical model. - Ecology 93: 368-377.

Carrete, M. and Tella, J. L. 2012. Is assisted colonisation feasible? Lessons from past introductions. - Front. Ecol. Environ. 10: $12-13$.

Carvalheiro, L. G. et al. 2008. Apparent competition can compromise the safety of highly specific biocontrol agents. - Ecol. Lett. 11: 690-700.
Cheptou, P. O. 2012. Clarifying Baker's law. - Ann. Bot. 109: 633-641.

Cheptou, P. O. et al. 2008. Rapid evolution of seed dispersal in an urban environment in the weed Crepis sancta. - Proc. Natl Acad. Sci. USA 105: 3796-3799.

Colautti, R. I. et al. 2009. Common garden comparisons of native and introduced plant populations: latitudinal clines can obscure evolutionary inferences. - Evol. Appl. 2: 187-199.

Coomes, D. A. et al. 2003. Factors preventing the recovery of New Zealand forests following control of invasive deer. - Conserv. Biol. 17: 450-459.

Cornelissen, J. H. C. et al. 1997. Foliar nutrients in relation to growth, allocation and leaf traits in seedlings of a wide range of woody plant species and types. - Oecologia 111: 460-469.

Coutts, S. et al. 2011. What are the key drivers of spread in invasive plants: dispersal, demography or landscape: and how can we use this knowledge to aid management? - Biol. Invas. 13: 1649-1661.

Darling, E. et al. 2008. Increased seed dispersal potential towards geographic range limits in a Pacific coast dune plant. - New Phytol. 178: 424-435.

Davidson, A. M. et al. 2011. Do invasive species show higher phenotypic plasticity than native species, and, if so, is it adaptive? A meta-analysis. - Ecol. Lett. 14: 419-431.

Dawson, W. et al. 2012. Common and rare plant species respond differently to fertilisation and competition, whether they are alien or native. - Ecol. Lett. 15: 873-880.

Dickie, I. A. et al. 2010. Co-invasion by Pinus and its mychorrhizal fungi. - New Phytol. 187: 475-484.

Dickie, I. A. et al. 2011. Ecosystem service and biodiversity tradeoffs in two woody successions. - J. Appl. Ecol. 48: 926-934.

Doak, D. F. and Morris, W. F. 2010. Demographic compensation and tipping points in climate-induced range shifts. - Nature 467: 959-962.

Driscoll, D. A. et al. 2010. Resolving conflicts in fire management using decision theory: asset-protection versus biodiversity conservation. - Conserv. Lett. 3: 215-223.

Elith, J. et al. 2010. The art of modelling range-shifting species. - Meth. Ecol. Evol. 1: 330-342.

Etterson, J. R. and Shaw, R. G. 2001. Constraint to adaptive evolution in response to global warming. - Science 294: 151-154.

Firn, J. et al. 2011. Abundance of introduced species at home predicts abundance away in herbaceous communities. - Ecol. Lett. 14: 274-281.

Franks, S. J. et al. 2007. Rapid evolution of flowering time by an annual plant in response to a climate fluctuation. - Proc. Natl Acad. Sci. USA 104: 1278-1282.

Fridley, J. D. et al. 2011. Soil heterogeneity buffers community response to climate change in species-rich grassland. - Global Change Biol. 17: 2002-2011.

Gobster, P. H. 2011. Factors affecting people's response to invasive species management. - In: Rotherham, I. D. and Lambert, R. A. (eds), Invasive and introduced plants and animals: human perceptions, attitudes and approaches to management. Earthscan, pp. 249-263.

Grevstad, F. S. 1999. Factors influencing the chance of population establishment: implications for release strategies in biocontrol. - Ecol. Appl. 9: 1439-1447.

Guisan, A. and Zimmermann, N. E. 2000. Predictive habitat distribution models in ecology. - Ecol. Modell. 135: 147-186.

Guisan, A. and Thuiller, W. 2005. Predicting species distribution: offering more than simple habitat models. - Ecol. Lett. 8: 993-1009.

Guisan, A. and Rahbek, C. 2011. SESAM - A new framework integrating macroecological and species distribution models for predicting spatio-temporal patterns of species assemblages. - J. Biogeogr. 38: 1433-1444. 
Hahn, M. A. et al. 2012. Increased population growth rate in invasive polyploid Centaurea stoebe in a common garden. - Ecol. Lett. 15: 947-954.

Hallett, S. G. 2006. Dislocation from coevolved relationships: a unifying theory for plant invasion and naturalization? - Weed Sci. 54: 282-290.

Heard, T. A. and Pettit, W. 2005. Review and analysis of the surveys for natural enemies of Mimosa pigra: what does it tell us about surveys for broadly distributed hosts? - Biol. Control 34: 247-254.

Heuberger, S. et al. 2010. Pollen- and seed-mediated transgene flow in commercial cotton seed production fields. - PLoS ONE 5: e14128.

Hierro, J. L. et al. 2005. A biogeographical approach to plant invasions: the importance of studying exotics in their introduced and native range. - J. Ecol. 93: 5-15.

Hobbs, R. J. et al. 2006. Novel ecosystems: theoretical and management aspects of the new ecological world order. - Global Ecol. Biogeogr. 15: 1-7.

Hobbs, R. J. et al. 2009. Novel ecosystems: implications for conservation and restoration. - Trends Ecol. Evol. 24: 599-605.

Hoegh-Guldberg, O. et al. 2008. Assisted colonisation and rapid climate change. - Science 321: 345-346.

Jarvis, P. J. et al. 2006. Predicting the economic benefits and costs of introducing new biological control agents for Scotch broom Cytisus scoparius into New Zealand. - Biol. Control 39: 135-146.

Jeltsch, F. et al. 2008. The state of plant population modelling in light of environmental change. - Perspect. Plant Ecol. Evol. Syst. 9: 171-189.

Jentsch, A. et al. 2007. A new generation of climate change experiments: events, not trends. - Front. Ecol. Environ. 5: 365-374.

Jiménez, M. A. et al. 2011. Extreme climatic events change the dynamics and invasibility of semi-arid annual plant communities. - Ecol. Lett. 14: 1227-1235.

Keane, R. M. and Crawley, M. J. 2002. Exotic plant invasions and the enemy release hypothesis. - Trends Ecol. Evol. 17: 164-170.

Kelly, A. E. and Goulden, M. L. 2008. Rapid shifts in plant distribution with recent climate change. - Proc. Natl Acad. Sci. USA 105: 11823-11826.

Kirkpatrick, M. and Barton, N. 1997. Evolution of a species' range. - Am. Nat. 150: 1-23.

Latimer, A. M. et al. 2009. Hierarchical models facilitate spatial analysis of large data sets: a case study on invasive plant species in the northeastern United States. - Ecol. Lett. 12: 144-154.

Lavergne, S. and Molofsky, J. 2007. Increased genetic variation and evolutionary potential drive the success of an invasive grass. - Proc. Natl Acad. Sci. USA 104: 3883-3888.

Lee, C. E. 2002. Evolutionary genetics of invasive species. - Trends Ecol. Evol. 17: 386-391.

Leifso, A. et al. 2012. Expansion of a globally pervasive grass occurs without substantial trait differences between home and away populations. - Oecologia 170: 1123-1132.

Lenoir, J. et al. 2008. Trait interactions help explain plant invasion success in the German flora. - J. Ecol. 96: 860-868.

Levidow, L. 2001. Precautionary uncertainty: regulating GM crops in Europe. - Soc. Stud. Sci. 31: 842-874.

Levine, J. M. 2000. Species diversity and biological invasions: relating local process to community pattern. - Science 288 : 852.

Lloret, F. et al. 2012. Extreme climatic events and vegetation: the role of stabilizing processes. - Global Change Biol. 18: 797-805.

Lonsdale, W. M. 1999. Global patterns of plant invasions and the concept of invasibility. - Ecology 80: 1522-1536.

Louda, S. M. et al. 2003. Nontarget effects - the Achilles' heel of biological control? Retrospective analyses to reduce risk associated with biocontrol introductions. - Annu. Rev. Entomol. 48: 365-396.
MacDougall, A. S. and Turkington, R. 2005. Are invasive species the drivers or passengers of change in degraded ecosystems? - Ecology 86: 42-55.

MacDougall, A. S. et al. 2008. Climatic variability alters the outcome of long-term community assembly. - J. Ecol. 96: 346-354.

Mackauer, M. 1976. Genetic problems in the production of biological control agents. - Annu. Rev. Entomol. 21: 369-385.

Mackenzie, B. F. and Larson, B. M. H. 2010. Participation under time constraints: landowner perceptions of rapid response to the emerald ash borer. - Society Nat. Resour. 23: 1013-1022.

McDonald-Madden, E. et al. 2011. Optimal timing for managed relocation of species faced with climate change. - Nature Climate Change 1: 261-265.

Melbourne, B. A. et al. 2007. Invasion in a heterogeneous world: resistance, coexistence or hostile takeover? - Ecol. Lett. 10: 77-94.

Midgley, G. F. et al. 2006. Migration rate limitations on climate change-induced range shifts in Cape Proteaceae. - Divers. Distrib. 12: 555-562.

Minteer, B. A. and Collins, J. P. 2010. Move it or lose it? The ecological ethics of relocating species under climate change. - Ecol. Appl. 20: 1801-1804.

Montoya, J. M. and Raffaelli, D. 2010. Climate change, biotic interactions and ecosystem services. - Phil. Trans. R. Soc. B 365: 2013-2018.

Moser, B. et al. 2011. Simulated migration in a long-term climate change experiment: invasions impeded by dispersal limitation, not biotic resistance. - J. Ecol. 99: 1229-1236.

Nathan, R. et al. 2011. Spread of North-American wind-dispersed trees in future environments. - Ecol. Lett. 14: 211-219.

Neubert, M. G. and Caswell, H. 2000. Demography and dispersal: calculation and sensitivity analysis of invasion speed for structured populations. - Ecology 81: 1613-1628.

Pagel, J. and Schurr, F. M. 2011. Forecasting species ranges by statistical estimation of ecological niches and spatial population dynamics. - Global Ecol. Biogeogr. 21: 293-304.

Petitpierre, B. et al. 2012. Climatic niche shifts are rare among terrestrial plant invaders. - Science 335: 1344-1348.

Pyšek, P. et al. 2009. The global invasion success of central European plants is related to distribution characteristics in their native range and species traits. - Divers. Distrib. 15: 891-903.

Pyšek, P. et al. 2010. Disentangling the role of environmental and human pressures on biological invasions across Europe. - Proc. Natl Acad. Sci. USA 107: 12157-12162.

Pyšek, P. et al. 2012. A global assessment of invasive plant impacts on resident species, communities and ecosystems: the interaction of impact measures, invading species' traits and environment. - Global Change Biol. 18: 1725-1737.

Ramula, S. et al. 2008. General guidelines for invasive plant management based on comparative demography of invasive and native plant populations. - J. Appl. Ecol. 45: 1124-1133.

Reid, A. M. et al. 2009. Does invasive plant management aid the restoration of natural ecosystems? - Biol. Conserv. 142: 2342-2349.

Rejmánek, M. and Richardson, D. M. 1996. What attributes make some plant species more invasive? - Ecology 77: 1655-1661.

Ricciardi, A. and Simberloff, D. 2009. Assisted colonisation is not a viable conservation strategy. - Trends Ecol. Evol. 24: 248-253.

Richards, C. L. et al. 2006. Jack of all trades, master of some? On the role of phenotypic plasticity in plant invasions. - Ecol. Lett. 9: 981-993.

Richardson, D. M. 2011. Invasion science: the roads travelled and the roads ahead. - In: Richardson, D. M. (ed.), Fifty years of invasion ecology. The legacy of Charles Elton. Wiley, pp. 397-407.

Richardson, D. M. and Cowling, R. M. 1992. Why is mountain fynbos invasible and which species invade? - In: Van Wilgen, 
B. W.et al. (eds), Fire in South African mountain fynbos. Springer, pp. 161-181.

Richardson, D. M. et al. 2009. Multidimensional evaluation of managed relocation. - Proc. Natl Acad. Sci. USA 106: 9721-9724.

Richardson, D. M. et al. 2011. Human-mediated introductions of Australian Acacia species-a global experiment in biogeography. - Divers. Distrib. 17: 771-787.

Richardson, P. J. et al. 2012. Inversion of plant dominancediversity relationships along a latitudinal stress gradient. - Ecology 93: 1431-1438.

Rout, M. E. and Callaway, R. M. 2009. An invasive plant paradox. - Science 324: 734-735.

Russell, B. D. et al. 2012. Predicting ecosystem shifts requires new approaches that integrate the effects of climate change across entire systems. - Biol. Lett. 8: 164-166.

Schlaepfer, D. R. et al. 2010. A multi-species experiment in their native range indicates pre-adaptation of invasive alien plant species. - New Phytol. 185: 1087-1099.

Schlaepfer, M. A. et al. 2011. The potential conservation value of non-native species. - Conserv. Biol. 25: 428-437.

Seastedt, T. R. et al. 2008. Management of novel ecosystems: are novel approaches required? - Front. Ecol. Environ. 6: 547-553.

Shea, K. and Chesson, P. 2002. Community ecology theory as a framework for biological invasions. - Trends Ecol. Evol. 17: 170-176.

Shea, K. et al. 1998. Management of populations in conservation, harvesting and control. - Trends Ecol. Evol. 13: 371-375.

Simberloff, D. and Von Holle, B. 1999. Positive interactions of nonindigenous species: invasional meltdown? - Biol. Invas. 1: 21-32.

Sloop, C. M. et al. 2011. Spatial and temporal genetic structure in a hybrid cordgrass invasion. - Heredity 106: 547-556.

Thuiller, W. et al. 2006. Will climate change promote alien plant invasions? - In: Nentwig, W. (ed.), Biological invasions. Springer, pp. 191-211.
Thuiller, W. et al. 2008. Predicting global change impacts on plant species' distributions: future challenges. - Perspect. Plant Ecol. Evol. Syst. 9: 137-152.

Van der Veken, S. et al. 2008. Garden plants get a head start on climate change. - Front. Ecol. Environ. 6: 212-216.

van Kleunen, M. et al. 2010. A meta-analysis of trait differences between invasive and non-invasive plant species. - Ecol. Lett. 13: 235-245.

van Kleunen, M. et al. 2011. Preadapted for invasiveness: do species traits or their plastic responses to shading differ between invasive and non-invasive plant species in their native range? - J. Biogeogr. 38: 1294-1304.

Vilà, M. et al. 2011. Ecological impacts of invasive alien plants: a meta-analysis of their effects on species, communities and ecosystems. - Ecol. Lett. 14: 702-708.

Vitt, P. et al. 2010. Assisted migration of plants: changes in latitudes, changes in attitudes. - Biol. Conserv. 143: 18-27.

Walther, G. R. 2004. Plants in a warmer world. - Perspect. Plant Ecol. Evol. Syst. 6: 169-185.

Walther, G. R. 2010. Community and ecosystem responses to recent climate change. - Phil. Trans. R. Soc. B 365: 2019-2024.

Ward, J. L. et al. 2012. Discordant introgression in a rapidly expanding hybrid swarm. - Evol. Appl. 5: 380-392.

Wardle, D. A. et al. 2011. Terrestrial ecosystem responses to species gains and losses. - Science 332: 1273-1276.

Wilson, J. R. U. et al. 2009. Something in the way you move: dispersal pathways affect invasion success. - Trends Ecol. Evol. 24: 136-144.

Yeates, A. et al. 2012. Biological control as an invasion process: disturbance and propagule pressure affect the invasion success of Lythrum salicaria biological control agents. - Biol. Invas. 14: 255-271.

Zavaleta, E. S. et al. 2001. Viewing invasive species removal in a whole-ecosystem context. - Trends Ecol. Evol. 16: 454-459.

Zhang, R. et al. 2011. Warming increases the spread of an invasive thistle. - PLoS ONE 6: e21725. 